\title{
Assessment of the argyrophilic nucleolar organizer region area/nucleus ratio in ovarian serous epithelial adenomas, borderline tumors and cancers
}

\author{
Leszek Gottwald ${ }^{1,2}$, Marian Danilewicz ${ }^{3}$, Jacek Suzin ${ }^{4}$, Malgorzata Wagrowska-Danilewicz ${ }^{3}$, Michal Spych', \\ Wieslaw Tylinski ${ }^{4}$ Katarzyna Topczewska-Tylinska ${ }^{6}$, Janusz Piekarski , Sylwia Kazmierczak-Lukaszewicz ${ }^{8}$, \\ Aleksandra Cialkowska-Rysz ${ }^{9}$
}

\author{
${ }^{1}$ Department of Radiotherapy, Chair of Oncology, Medical University of Lodz, Poland \\ ${ }^{2}$ Department of Radiotherapy, Regional Cancer Center, \\ Copernicus Memorial Hospital of Lodz, Poland \\ ${ }^{3}$ Department of Nephropathology, Division of Morphometry, Medical University of Lodz, \\ Poland \\ ${ }^{4}$ Department of Gynecology and Gynecologic Oncology, \\ First Chair of Obstetrics and Gynecology, Medical University of Lodz, Poland \\ ${ }^{5}$ Department of Radiotherapy and General Oncology, Regional Cancer Center, \\ Copernicus Memorial Hospital of Lodz, Poland \\ ${ }^{6}$ Department of Health Care Policy, Medical University of Lodz, Poland \\ ${ }^{7}$ Department of Surgical Oncology, Chair of Oncology, Medical University of Lodz, Poland \\ ${ }^{8}$ Department Chemotherapy, Regional Cancer Center, \\ Copernicus Memorial Hospital of Lodz, Poland \\ ${ }^{9}$ Palliative Care Unit, Chair of Oncology, Medical University of Lodz, Poland
}

Submitted: 8 August 2010

Accepted: 26 September 2010

Arch Med Sci 2013; 9, 1: 79-85

DOI: $10.5114 /$ aoms.2013.33066

Copyright (c) 2013 Termedia \& Banach

\begin{abstract}
Introduction: There is a need to assess the value of the novel potentially useful biomarkers in ovarian tumors. The aim of study was to assess the value of sAgNOR analysis in ovarian serous epithelial tumors.

Material and methods: The analysis was performed in ovaries from 113 patients treated operatively due to serous ovarian tumors (30 adenomas, 14 borderline tumors and 69 cancers). After silver staining of paraffin specimens from surgery, sAgNOR in tumor cells was analyzed. Additionally, the value of the argyrophilic nucleolar organizer region area/nucleus ratio (SAgNOR) in the prediction of disease-free survival (DFS) and overall survival (OS) in 52 patients with serous ovarian cancer with complete follow-ups in November 2009 was evaluated. Age, grading, radicality of surgery and FIGO staging were analyzed as additional factors. Results: SAgNOR in adenomas, borderline tumors and cancers was in the following ranges: $(0.73 \pm 0.23) \times 10^{6},(0.81 \pm 0.18) \times 10^{6}$ and $(0.96 \pm 0.33) \times 10^{6}$ $\left[\mathrm{AgNOR} / \mathrm{cm}^{2}\right]$ respectively. In cancers from $\mathrm{G} 1$ to $\mathrm{G} 3 \mathrm{sAgNOR}$ was $(1.02 \pm 0.32)$ $\times 10^{6}(\mathrm{G} 1),(0.98 \pm 0.37) \times 10^{6}(\mathrm{G} 2)$ and $(0.82 \pm 0.24) \times 10^{6}(\mathrm{G} 3)\left[\mathrm{AgNOR} / \mathrm{cm}^{2}\right]$ respectively. In univariate analysis, but not in multivariate analysis, staging negatively correlated with better DFS and OS. SAgNOR, age of patients, grading and radicality of surgery were not associated with DFS or OS in either univariate or multivariate analysis.

Conclusions: SAgNOR analysis is not sufficient to precisely characterize cellular kinetics in serous ovarian tumors, and the analysis of sAgNOR, mAgNOR and pAgNOR should be performed commonly. The prognostic significance of sAgNOR in patients with serous ovarian cancer was not proven.
\end{abstract}

Key words: nucleolar organizer regions, argyrophilic, ovarian tumors, serous.

\author{
Corresponding author: \\ Leszek Gottwald MD, PhD \\ Department of Radiotherapy \\ Chair of Oncology \\ Medical University of Lodz \\ 4 Paderewskiego Str. \\ 93-509 Lodz, Poland \\ Phone: +48 426895551 \\ Fax: +48 426895552 \\ E-mail: lgottwald@wp.pl
}




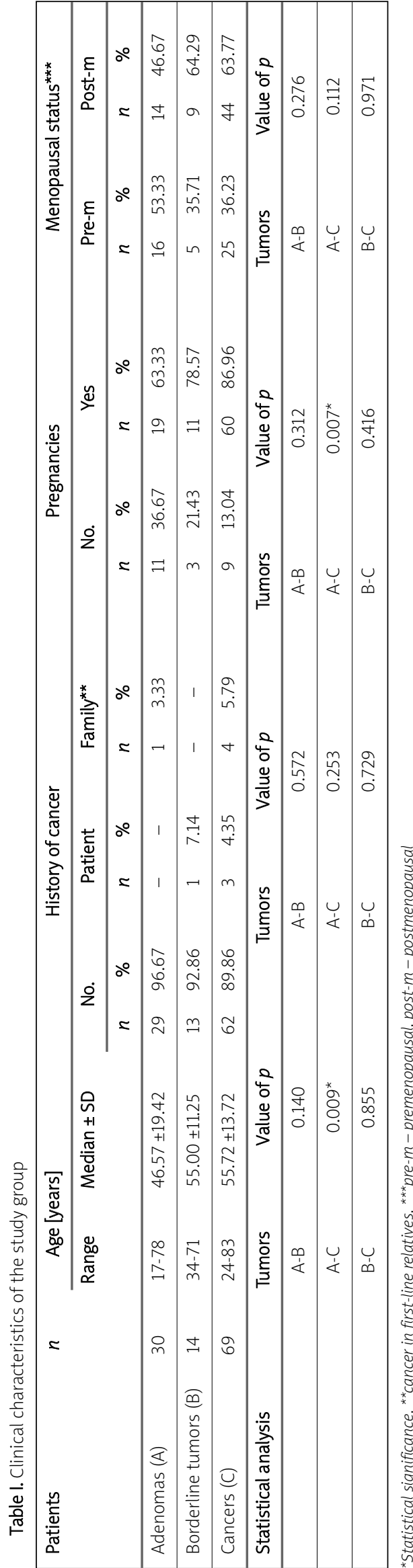

\section{Introduction}

Neoplastic tumors arising from the surface epithelium of the ovary comprise a broad spectrum of neoplasms, ranging from serous to endometrioid, mucinous, transitional, clear cell and undifferentiated tumor types [1]. These histotypes have been recently associated with distinct molecular profiles, making it reasonable to conceive that the clinical outcome of molecular pathways may strongly affect the response to different drugs and the clinical outcome of patients [2, 3]. The most common primary ovarian cancer is of the serous histotype [1-3].

Many studies have been devoted to finding specific biomarkers in ovarian epithelial tumors and numerous features with varying degrees of accuracy have been described [4-7]. The analysis of the argyrophilic nucleolar organizer regions (AgNORs) is one of the methods [8]. Nucleolar organizer regions are segments of DNA that transcribe to ribosomal RNA and are situated on short arms of the acrocentric chromosomes $13,14,15,21$ and 22. The number of NORs is related to the cell cycle and the quantity of interphase NORs increases in cycling cells from the early $\mathrm{G} 1$ phase to the late $\mathrm{S}$ phase. In cancer tissues the number of NORs is closely related to both the percentage of cycling cells and S-phase cells $[9,10]$.

After silver staining, NORs can be easily identified as black dots exclusively situated throughout the nucleolar area, and are called AgNORs. NOR argyrophilia is due to a group of nucleolar proteins with a high affinity to silver. AgNOR analysis can be performed in three ways: I - the mean number of AgNORs per nucleus (mAgNOR), II - the mean percentage of nuclei with five or more AgNORs per nucleus (pAgNOR), III - the AgNOR area/nucleus ratio (sAgNOR) [11]. In our previous studies we analyzed the value of $\mathrm{mAgNOR}$ and $\mathrm{pAgNOR}$ but not sAgNOR in serous ovarian tumors [12-14].

The aim of the study was to assess: the value of sAgNOR analysis in ovarian serous epithelial adenomas, borderline tumors and cancers, the value of sAgNOR analysis in the prediction of disease-free survival (DFS) and overall survival (OS) in serous ovarian cancer.

\section{Material and methods}

The study included ovary tumors from 113 consecutive patients $17-83$ years old $(53.21 \pm 15.58)$ diagnosed and treated operatively for serous ovarian tumor (30 benign, 14 borderline and 69 cancers) in the Madurowicz Memorial Hospital of Lodz during 1998-2002. Detailed clinical characteristics of the study group are presented in Table I.

The tissues from surgery were analyzed. Sections $4 \mu \mathrm{m}$ thick were cut from tissue blocks, previously routinely fixed in 10\% buffered formalin and embedded in paraffin. One section was stained with hematoxylin and eosin for histopathologic diagnosis. Another sec- 
tion was stained according to the one-step AgNOR method described by Howell and Black [10] and Ploton et al. [15]: specimens were incubated in a mixture of one volume $2 \%$ gelatin in $1 \%$ formic acid to two volumes $50 \%$ silver nitrate and then washed ten times with deionized distilled water. Histological morphometry was performed by means of an image analysis system consisting of a PC equipped with an optical mouse, a Ver 2000 card (frame grabber, true color, real time), produced by ADDA Technologies (Taiwan), and a Panasonic color TV camera (Japan), coupled to a Carl Zeiss Jenaval microscope (Germany). This system was programmed (MultiScan software produced by Computer Scanning Systems, Poland) to calculate the surface area of the structure whose perimeter was traced, and the total number of objects (semi-automatic function).

Both the counting of AgNORs and the morphometric assessment were performed at 400× magnification. AgNORs were seen as black or dark brown dots within the nucleus. The following parameters were estimated in 100 randomly chosen nuclei: (1) nuclear area and nuclear outline (the outer limit of a nuclear membrane was traced using the cursor of an optical mouse), (2) the number of AgNORs per nuclear area (these objects were automatically counted and then followed with manual correction, as needed). The randomization was made by the operator. From these data the analysis of sAgNOR was conducted. The sAgNOR was correlated with the tumor type and in cancers additionally with histological grading and clinical staging.

Afterwards the analysis of survival as a function of sAgNOR was conducted. From the group of 69 pa- tients with serous ovarian cancer we examined 52 patients aged $24-83$ years $(57.17 \pm 14.51)$. Patients with incomplete follow-ups in November 2009 were excluded. Detailed clinical and pathological characteristics of the group are presented in Table II. Additional factors included in the analysis were age at diagnosis, clinical FIGO staging, radicality of surgery (1. radical: lack of residual tumor, 2. optimal cytoreduction: $\leq 1.0 \mathrm{~cm}$ diameter of residual tumor, 3. suboptimal cytoreduction: $>1.0 \mathrm{~cm}$ diameter of residual tumor) and histological grading. Disease-free survival was defined as the period from primary surgery until relapse. OS was defined as the period from primary surgery until death or until complete follow-up.

\section{Statistical analysis}

All data were analyzed using CSS Statistica software (StatSoft Inc., Tulsa, OK., USA). Student's t-test, as a statistical method, was used to define differences between mean values of sAgNOR in serous ovarian adenomas, borderline tumors and G1-3 cancers in stages I + II and III + IV and to compare the mean values of age at diagnosis. The $\chi^{2}$ test and Fisher's test were used to compare the history of cancer, number of pregnancies and menopausal status of patients. Spearman's rank correlation was used to correlate the sAgNOR and patients' age, tumor type, grading and FIGO staging. Kaplan and Meier survival curves were calculated using univariate survival analysis. The log-rank test was used to compare survival curves by obtaining a $\chi^{2}$ value. A value of $p$ less than 0.05 was considered signifi-

Table II. Analysis of survival in 52 patients with serous ovarian cancer

\begin{tabular}{|c|c|c|c|c|c|c|c|c|c|c|c|}
\hline \multirow[t]{2}{*}{ Parameter } & & \multirow[t]{2}{*}{$n$} & \multirow[t]{2}{*}{$\%$} & \multicolumn{4}{|c|}{ DFS } & \multicolumn{4}{|c|}{ OS } \\
\hline & & & & $\begin{array}{c}\text { Hazard } \\
\text { ratio }\end{array}$ & $\begin{array}{r}95 \% \text { Co } \\
\text { inte }\end{array}$ & $\begin{array}{l}\text { fidence } \\
\text { val }\end{array}$ & $\begin{array}{l}\text { Value } \\
\text { of } p\end{array}$ & $\begin{array}{c}\text { Hazard } \\
\text { ratio }\end{array}$ & $95 \%$ & $\begin{array}{l}\text { nfidence } \\
\text { erval }\end{array}$ & $\begin{array}{c}\text { Value } \\
\text { of } p\end{array}$ \\
\hline \multirow[t]{3}{*}{ Age [years] } & $\leq 50(\mathrm{~A})$ & 14 & 26.92 & & & & & & & & \\
\hline & $51-70(B)$ & 21 & 40.40 & 1.235 & 53.07 & 61.11 & 0.448 & 1.235 & 53.09 & 61.14 & 0.294 \\
\hline & $>70(\mathrm{C})$ & 17 & 32.68 & & & & & & & & \\
\hline \multirow[t]{3}{*}{ Grading } & G1 & 13 & 25.00 & & & & & & & & \\
\hline & G2 & 15 & 28.84 & 1.134 & 1.92 & 2.41 & 0.651 & 1.134 & 1.98 & 2.44 & 0.685 \\
\hline & G3 & 24 & 46.16 & & & & & & & & \\
\hline \multirow[t]{4}{*}{ Staging } & I & 9 & 17.31 & & & & & & & & \\
\hline & $\|$ & 5 & 9.62 & 1.713 & 2.44 & 2.93 & 0.091 & 1.713 & 2.45 & 2.97 & 0.114 \\
\hline & III & 31 & 59.62 & & & & & & & & \\
\hline & IV & 7 & 13.45 & & & & & & & & \\
\hline \multirow[t]{3}{*}{ Radicality of surgery* } & $\mathrm{R}$ & 16 & 30.77 & & & & & & & & \\
\hline & OC & 30 & 57.69 & 1.075 & 2.04 & 2.63 & 0.748 & 1.075 & 2.07 & 2.66 & 0.889 \\
\hline & SoC & 6 & 11.54 & & & & & & & & \\
\hline \multicolumn{4}{|c|}{$\mathrm{sAgNOR}\left[\mathrm{AgNOR} / \mathrm{cm}^{2}\right]$} & 0.954 & 2.30 & 3.11 & 0.734 & 0.954 & 2.36 & 3.14 & 0.846 \\
\hline
\end{tabular}

${ }^{\star} R$ - radical, OC - optimal cytoreduction, SoC - suboptimal cytoreduction 
cant. A multivariate proportional hazard model (Cox) was used to test the prognostic value of features.

\section{Results}

\section{The analysis of sAgNOR in ovaries from 113 patients treated operatively for serous ovarian tumor}

A correlation between age and SAgNOR in patients with serous ovarian adenomas $(\delta=0.177$; $p=0.351)$, borderline tumors $(\delta=-0.059 ; p=0.840)$ and cancers $(\delta=0.169 ; p=0.167)$ was not found. Lower sAgNOR was found in benign adenomas than in cancers ( $p=0.008$ ) but not when compared to sAgNOR in borderline tumors $(p=0.267)$. A significant relationship in SAgNOR between borderline tumors and cancers was not found ( $p=0.103$ ) (Figure 1).

In $\mathrm{G} 1$ cancers SAgNOR was higher than in G3 cancers ( $p=0.029$ ) but not when compared to sAgNOR in $\mathrm{G} 2$ cancers $(p=0.714)$. A significant relationship in sAgNOR between $\mathrm{G} 2$ and $\mathrm{G} 3$ cancers was not found ( $p=0.118$ ) (Figure 2). sAgNOR in early staged (FIGO stages I-II) and advanced (FIGO stages III-IV) serous ovarian cancer was similar $(p=0.539)$. A correlation between sAgNOR and staging was not proven $(\delta=0.028 ; p=0.820)$. The statistical analysis of SAgNOR as a function of tumor type, histological grading and clinical staging is presented in Table III. Figures 3-5 show the AgNORs in serous ovarian adenoma, borderline tumor and G3 cancer, respectively.

\section{The analysis of survival as function of sAgNOR, age of patients, grading, FIGO staging and radicality of surgery in 52 patients with serous ovarian cancer}

The follow-up period was 2-143 months (44.6 $\pm 43.4)$. The DFS rate was $15.4 \%$, and the OS rate was $21.2 \%$. In univariate analysis only staging negatively correlated with better DFS and OS $(p=0.016$, $p=0.020$ respectively). sAgNOR ( $p=0.065$ - Figure 6; $p=0.109-$ Figure 7$)$, age of patients $(p=0.102$;

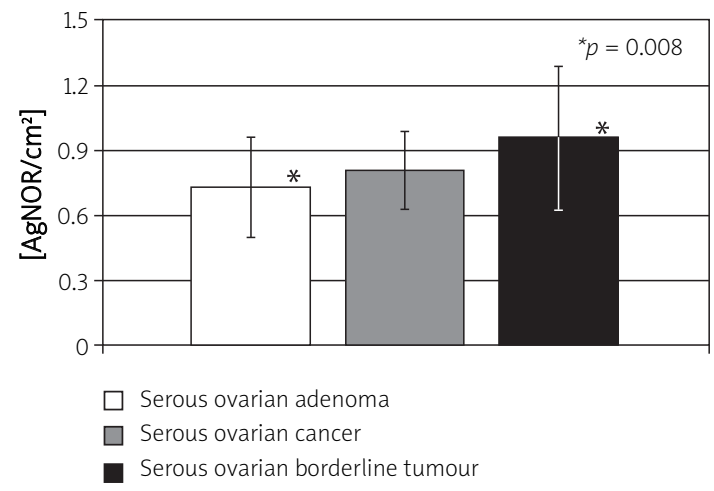

Figure 1. sAgNOR in ovarian serous epithelial adenomas, borderline tumors and cancers $p=0.158)$, grading $(p=0.167 ; p=0.120)$ and radicality of surgery $(p=0.156 ; p=0.066)$ were not associated with DFS or OS. In multivariate analysis no correlations of DFS or OS with sAgNOR, age of patients, grading, FIGO staging or radicality of surgery were proven (Table II).

\section{Discussion}

Silver staining is an easy and quick technique that can be performed on formalin-fixed paraffinembedded sections, which enables accurate assessment of the changes in AgNOR patterns in tumor cell nuclei, and might provide new information on tumor biology [9-11, 15, 16]. The relationship between AgNOR count, age and performance status of the patients is not proven. It is known that in more rapidly proliferating tumors, AgNORs become disaggregated within the nucleus and nucleolus and the number of AgNORs increases [11]. It is postulated that in benign tumors of different origin, the $m A g N O R$ value varies between one and two, and an increased $\mathrm{mAgNOR}$ value positively correlates with the number of acrocentric chromosomes, increased amount of DNA and aneuploidy [17]. An $\mathrm{mAgNOR}$ value larger than three is thought to be a characteristic marker of malignant tumors $[11,18]$.

The role of the AgNOR method in gynecological oncology was proven [8], and some reports describing the value of AgNOR assessment in epithelial ovarian tumors exist in the literature as well [7, 12-14, $16,19-28]$. Unfortunately, most of the studies were conducted in groups with heterogeneous histotypes of ovarian cancers, despite the distinct molecular profiles and the clinical outcome of patients, and only a few reports on homogeneous groups of ovarian epithelial neoplasms have been published [12-14, 16, 19-23].

The results of our previous studies in a homogeneous group of 113 ovarian serous epithelial tumors are similar to those published by Stemberger-Papic et al. ( 59 cases: 20 benign, 19 borderline and 20 cancers) [19] and confirmed that in ovarian serous epi-

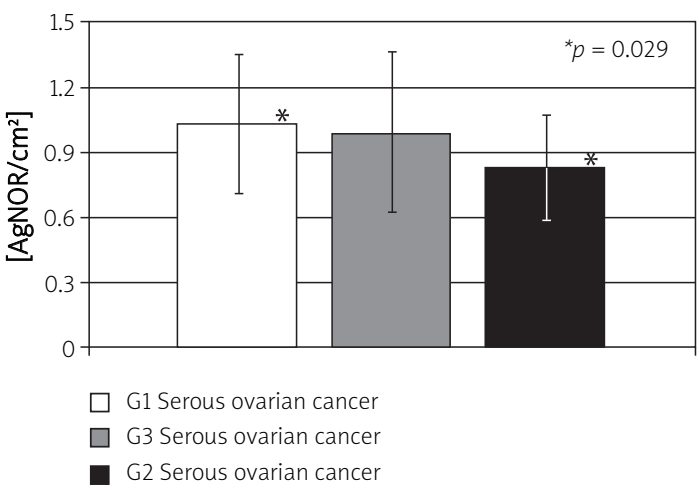

Figure 2. sAgNOR and grading in ovarian serous epithelial cancer 
Table III. sAgNOR analysis in serous ovarian adenomas, borderline tumors and cancers

\begin{tabular}{|c|c|c|c|c|c|c|c|c|}
\hline \multirow{2}{*}{$\begin{array}{l}\text { Characteristics } \\
\text { of tumors }\end{array}$} & \multirow[t]{2}{*}{$n$} & \multirow[t]{2}{*}{$\%$} & \multicolumn{4}{|c|}{ sAgNOR $\left[\mathrm{AgNOR} / \mathrm{cm}^{2}\right]$} & \multicolumn{2}{|c|}{ Statistical analysis } \\
\hline & & & Min & Max & Median & SD & Parameters & Value of $p$ \\
\hline Adenomas (A) & 30 & 26.55 & $0.38 \times 10^{6}$ & $1.52 \times 10^{6}$ & $0.73 \times 10^{6}$ & $0.23 \times 10^{6}$ & $A-B$ & 0.267 \\
\hline Borderline tumors (B) & 14 & 12.39 & $0.56 \times 10^{6}$ & $1.13 \times 10^{6}$ & $0.81 \times 10^{6}$ & $0.18 \times 10^{6}$ & $A-C$ & $0.008^{*}$ \\
\hline Cancers (C) & 69 & 61.06 & $0.41 \times 10^{6}$ & $2.40 \times 10^{6}$ & $0.96 \times 10^{6}$ & $0.33 \times 10^{6}$ & $\mathrm{~B}-\mathrm{C}$ & 0.103 \\
\hline \multicolumn{9}{|l|}{ Grading: } \\
\hline G1 & 31 & 44.93 & $0.66 \times 10^{6}$ & $2.28 \times 10^{6}$ & $1.02 \times 10^{6}$ & $0.32 \times 10^{6}$ & G1-G2 & 0.714 \\
\hline $\mathrm{G} 2$ & 21 & 30.43 & $0.66 \times 10^{6}$ & $2.40 \times 10^{6}$ & $0.98 \times 10^{6}$ & $0.37 \times 10^{6}$ & G1-G3 & $0.029^{*}$ \\
\hline $\mathrm{G3}$ & 17 & 24.64 & $0.41 \times 10^{6}$ & $1.35 \times 10^{6}$ & $0.82 \times 10^{6}$ & $0.24 \times 10^{6}$ & G2-G3 & 0.118 \\
\hline \multicolumn{9}{|l|}{ Staging: } \\
\hline I + II (S1) & 14 & 20.29 & $0.41 \times 10^{6}$ & $1.38 \times 10^{6}$ & $0.91 \times 10^{6}$ & $0.26 \times 10^{6}$ & S1-S2 & 0.539 \\
\hline III + IV (S2) & 55 & 79.71 & $0.51 \times 10^{6}$ & $2.40 \times 10^{6}$ & $0.97 \times 10^{6}$ & $0.34 \times 10^{6}$ & & \\
\hline
\end{tabular}

*Statistical significance

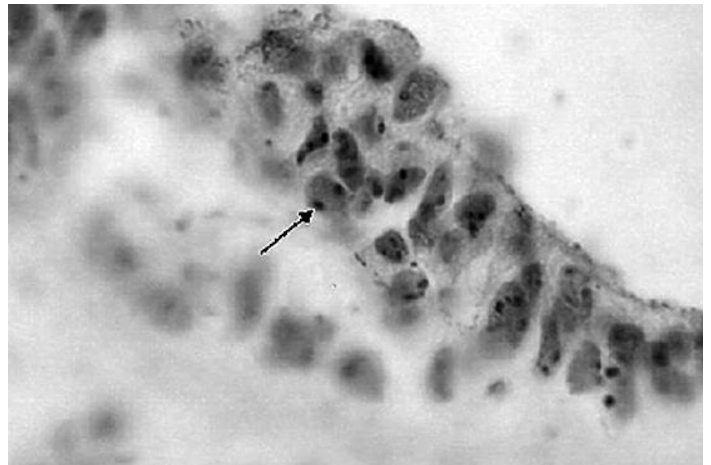

Figure 3. AgNORs in ovarian serous epithelial adenoma, 1000× magnification. After silver staining, NORs can be easily identified as black dots exclusively situated throughout the nucleolar area, and are called AgNORs (arrows)

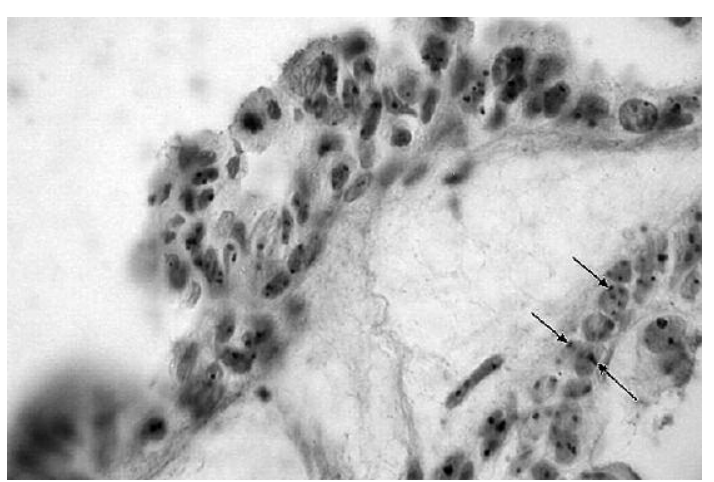

Figure 5. AgNORs in G3 ovarian serous epithelial cancer, $1000 \times$ magnification. The total number of AgNORs (arrows) per nucleus significantly increases from G1 to $\mathrm{G} 3$ serous ovarian cancers

thelial tumors the total number of AgNORs increases from benign to borderline and malignant neoplasms $[8,13]$. In the homogeneous group of ovarian mucinous epithelial tumors Versa-Ostojić et al. (46 cases: 16 benign, 15 borderline and 15 cancers) [20] and Ter-

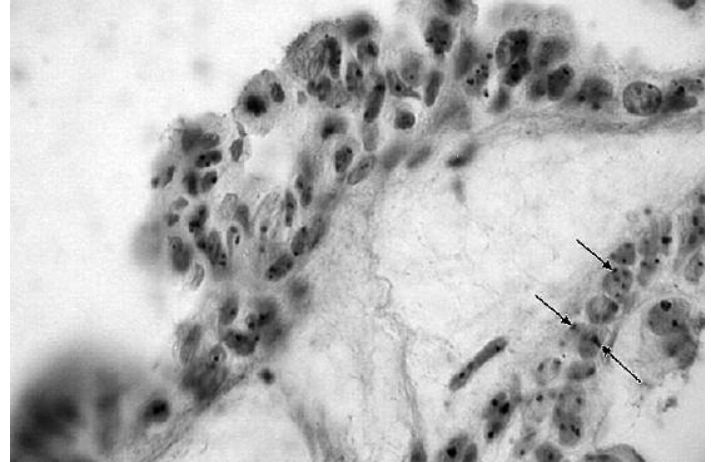

Figure 4. AgNORs in ovarian serous epithelial borderline tumor, 1000× magnification. The total number of AgNORs (arrows) per nucleus increases from benign adenomas to borderline tumors

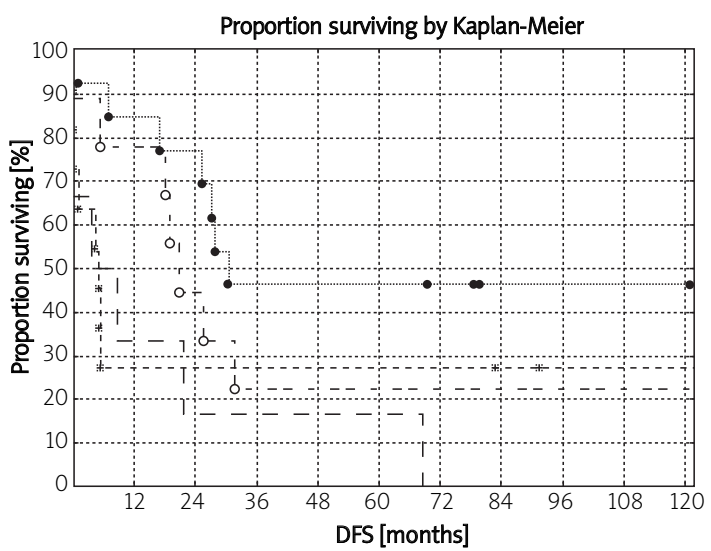

$<0.80 \times 10^{6} \mathrm{AgNOR} / \mathrm{cm}^{2}$

$0.80-0.89 \times 10^{6} \mathrm{AgNOR} / \mathrm{cm}^{2}$

$0.90-0.99 \times 10^{6} \mathrm{AgNOR} / \mathrm{cm}^{2}$

$1.00-1.09 \times 10^{6} \mathrm{AgNOR} / \mathrm{cm}^{2}$

$>1.09 \times 10^{6} \mathrm{AgNOR} / \mathrm{cm}^{2}$

Figure 6. sAgNOR analysis and DFS - univariate analysis 


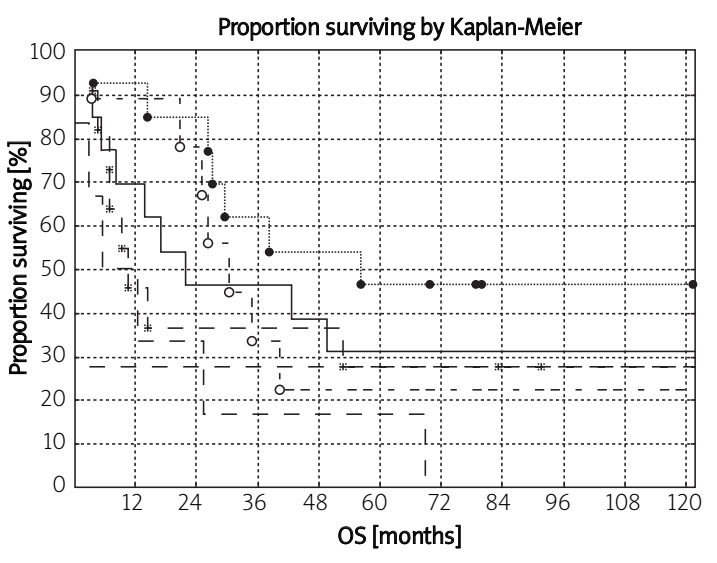

$<0.80 \times 10^{6} \mathrm{AgNOR} / \mathrm{cm}^{2}$

$0.80-0.89 \times 10^{6} \mathrm{AgNOR} / \mathrm{cm}^{2}$

$0.90-0.99 \times 10^{6} \mathrm{AgNOR} / \mathrm{cm}^{2}$

$1.00-1.09 \times 10^{6} \mathrm{AgNOR} / \mathrm{cm}^{2}$

$>1.09 \times 10^{6} \mathrm{AgNOR} / \mathrm{cm}^{2}$

Figure 7. sAgNOR analysis and OS - univariate analysis

likowski et al. (39 cases: 14 benign, 14 borderline and 11 cancers) [21] reported similar results. In our previous studies, an analysis of the homogeneous group of ovarian serous epithelial tumors as a function of sAgNOR was not conducted, and now we have completed it. Our results have confirmed the increase in sAgNOR from benign adenomas to cancers too, and they are similar to the results of Stemberger-Papic et al. [19].

Several studies have shown that the total number of AgNORs varies among cancers of various origin with different histological grades $[8,17,18,29]$. In our previous study we reported a significant increase in mAgNOR and pAgNOR from G1 to G3 serous ovarian cancers [12]. Now we have found higher sAgNOR in G1 cancers than in $\mathrm{G} 3$ cancers. This can be explained by the dynamic changes in the nuclear volume during the transformation from well-differentiated to poorly differentiated carcinoma cells, which is characterized by increased protein synthesis, resulting in an increase in number and area of the nucleus [19]. Despite the dynamic increase in the total number of AgNORs per tumor cell nucleus from G1 to G3 cancers [12], which is closely related to rRNA [11], the rapid increase in cell volume may result in the decrease of sAgNOR from G1 to G3 serous ovarian cancers. This finding is original, and there is a need for further prospective studies in larger populations of ovarian cancer patients to confirm it.

The relationship between the total number of AgNORs in many cancers and some clinical parameters including staging, tumor size and distant metastasis has also been widely described [8]. The potential value of AgNOR analysis for distinguishing the character of peritoneal fluid was confirmed by Sujathan et al. [30]. Ghazizadeh et al. [26] and Sah et al. [27] described a positive correlation between the total number of AgNORs and clinical staging in patients with ovarian cancer. In our previous study we confirmed a significant association between staging and mAgNOR and pAgNOR in serous ovarian cancer as well [13]. Our present results in the same group show that the third parameter of AgNOR analysis, SAgNOR, remains rather constant during the progression and dissemination of the disease.

The value of AgNORs to predict long-term survival in patients with primary ovarian cancer has not been clearly explained yet [14, 27, 28]. Our previous studies examined 39 patients with a short observation period from initial surgery to secondlook laparotomy. We found higher mAgNOR and pAgNOR to be related to a better response to adjuvant chemotherapy [14]. It is noteworthy that early relapses occur in tumors with high proliferative activity after remission, and generally prognosis for these patients is worse compared to patients with lower proliferative activity. Analyzing long-term treatment results, Muso found the number of AgNORs significantly higher in 37 patients with progressive ovarian cancer of different histological types, despite postoperative chemotherapy, compared to a group of patients who had undergone successful treatment [28]. Similarly, Sah et al. observed high AgNOR counts in a group of 84 patients with progressive disease, recurrence or death from tumor [27]. Our material does not confirm the above-mentioned observations and we found only the FIGO staging to be a valuable indicator of survival in univariate analysis.

In conclusion, SAgNOR is not a sufficient parameter to precisely characterize cellular kinetics in serous ovarian tumors, and the analysis of sAgNOR, mAgNOR and pAgNOR should be performed commonly. The prognostic significance of SAgNOR analysis in patients with serous ovarian cancer was not proven, but due to the small number of patients further prospective studies in larger populations are needed to assess the potential prognostic value of AgNOR count in ovarian cancer patients.

\section{References}

1. Seidman JD, Russell P, Kurman RJ. Surface epithelial tumors oft he ovary. In: Kurman RJ (ed). Blaustein's pathology of the female genital tract. Kurman RJ (ed). New York: Springer-Verlag 2002; 791-904.

2. Kurman RJ, Shih IM. Pathogenesis of ovarian cancer: lessons from morphology and molecular biology and their clinical implications. Int J Gynecol Pathol 2008; 27: 151-60.

3. Ozgun MT, Turkyilmaz C. A giant ovarian mucinous cystadenoma in an adolescent: a case reprt. Arch Med Sci 2009; 5: 281-3.

4. Cotichia CM, Yang J, Moses MA. Ovarian cancer biomarkers: current options and future promise. J Natl Compr Canc Netw 2008; 6: 795-802.

5. Gora E, Zelazowski MJ, Gottwald L, Bienkiewicz A, Bednarek $A K$. Detection of circulating carcinoma in peripheral 
blood collected from patients with ovarian cancer by using different molecular markers - a preliminary report. Arch Med Sci 2006; 2: 101-7.

6. Rzymski P. Tumor necrosis factor receptors p53 and p75 and ovarian cancer - state-of-the-art research and clinical implications. Arch Med Sci 2005; 1: 3-7.

7. Kalloniemi OP, Punnonen R, Mattila J, Lehtinen M, Koivula T. Prognostic significance of DNA index, multiploidy and S-phase fraction in ovarian cancer. Cancer 1988; 61: 334-9.

8. Gottwald L, Danilewicz M, Korczynski J, Bienkiewicz A. Assessment of argyrophylic nucleolar organizer regions (AgNORs) in gynecological oncology. Prz Menopauz 2005; 17: 28-32.

9. Sirri V, Roussel P, Hernandez-Verdun D. The AgNOR proteins: qualitative and quantitative changes during the cell cycle. Micron 2000; 31: 121-6.

10. Howell WM, Black DA. Controlled silver-staining of nucleolus organizer regions with a protective colloidal developer: a 1-step method. Experimentia 1980; 36: 1014-5.

11. Crocker J, Boldy D, Egan M. How should we count AgNORs? Proposals for a standardized approach. J Pathol 1989; 158: 185-8.

12. Gottwald L, Danilewicz M, Suzin J, Bienkiewicz A. The assesment of argyrophylic nucleolar organizer regions (AgNORs) count in serous ovarian neoplasms. Prz Menopauz 2003; 2: 38-41.

13. Gottwald L, Danilewicz M, Suzin J, Bienkiewicz A. Assessment of the AgNORs count in serous ovarian cancer. Ginekol Pol 2004; 75: 770-5.

14. Gottwald L, Danilewicz M, Suzin J, Wójcik-Krowiranda K, Bienkiewicz A. AgNORs count correlates better than grading with the effect of chemotherapy in serous ovarian cancer. Pol J Pathol 2003; 54: 239-42.

15. Ploton D, Menager M, Jeannesson P, Himber G, Pigeon F, Adnet J. Improvement in the staining and in the visualiza tion of the argyrophilic proteins of the Nucleolar Organizer Regions at the optical level. Histochem J 1986; 18: 5-14.

16. Mauri FA, Scampini S, Aldovini D, et al. AgNOR distribution in serous tumours of the ovary. Pathologica 1990; 82: 487-92.

17. Mourad WA, Setrakian S, Hales ML, Abdulla M, Trucco G. The argyrophilic nucleolar organizer regions in ductal carcinoma in situ of the breast. Cancer 1994; 74: 1739-5.

18. Ceccarelli C, Trere D, Santini D, Taffurelli M, Chieco P, Derenzini M. AgNORs in breast tumours. Micron 2000; 31: 143-9.

19. Stemberger-Papić S, Stanković C, Vrdoljak-Mozetić D, et al. Morphometry and digital AgNOR analysis in cytological imprints of benign, borderline and malignant serous ovarian tumours. Cytopathology 2006; 17: 382-9.

20. Versa-Ostojić D, Stanković T, Stemberger-Papić S, et al. Nuclear morphometry and AgNOR quantification: compu terized image analysis on ovarian mucinous tumor imprints. Anal Quant Cytol Histol 2008; 30: 160-8.

21. Terlikowski S, Sulkowski S, Lenczewski A, Musiatowicz B, Kulikowski M. Study of borderline and invasive mucinous ovarian tumors using Ki-67 (MIB 1) antibodies and nucleolar organizer region (NOR) staining. Arch Gynecol Obstet 1999; 263: 29-33.

22. Trabucco S, Varcaccio-Garofalo G, Botticella MA, De Stefano R, Capursi T, Resta L. Expression of AgNORs in serous ovarian tumors. Eur J Gynecol Oncol 1994; 15: 222

23. Terlikowski S, Lenczewski A, Famulski W, Sulkowski S, Kulikowski M. Expression of nucleolar organizer regions (NORs) in ovarian epithelial tumors. Folia Histochem Cytobiol 2001; 39: 161-2.

24. Criscuolo M, Martinelli AM, Migaldi M, et al. Prognostic sig nificance of nucleolar organizer regions in ovarian epithe lial tumors. Int J Gynecol Pathol 1993; 12: 259-63.
25. Zergeroglu S, Aksakal O, Demirturk F, Gokmen O. Prognostic importance of the nucleolar organizer region score in ovarian epithelial tumors. Gynecol Obstet Invest 2001; 51: 60-3.

26. Ghazizadeh M, Sasaki Y, Araki T, Konishi H, Aihara K. Prognostic value of proliferative activity of ovarian carcinoma as revealed by PCNA and AgNOR analyses. Am J Clin Pathol 1997; 107: 451-8.

27. Sah SP, Dawar R, Kumar L, Gupta SD. Nucleolar organizer regions as a prognostic indicator in epithelial cancers of the ovary. Int J Gynecol Pathol 2004; 23: 347-53.

28. Muso H. Long-term prognostic factors for chemotherapy of ovarian cancer. Osaka City Med J 1998; 44: 155-71.

29. Ofner D, Schmid KW. Standardized AgNOR analysis: its usefulness in surgical oncology. Histochem Cell Biol 1996; 106: 193-6.

30. Sujathan K, Kannan S, Raveendran-Pillai K, Chandralekha B, Sreedevi-Amma N, Krishnan-Nair M. Significance of AgNOR count in differentiating malignant cells from reactive mesothelial cells in serous effusions. Acta Cytologica 1996; 40: 724-8. 